\title{
CORRIGENDUM
}

\section{Plasmonics for improved photovoltaic devices}

Harry A. Atwater and Albert Polman

Nature Materials 9, 205-213 (2010); published online 19 February 2010; corrected online 1 September 2010.

In Fig. 1a of the version of this Review originally published, the graph labelled ' $2-\mu \mathrm{m}$-thick Si wafer' is that for a 10- $\mu$ m-thick Si wafer. The corrected figure is shown below. The original figure caption and descriptions in the text are correct. The figure has been corrected in the HTML and PDF versions of this Review.

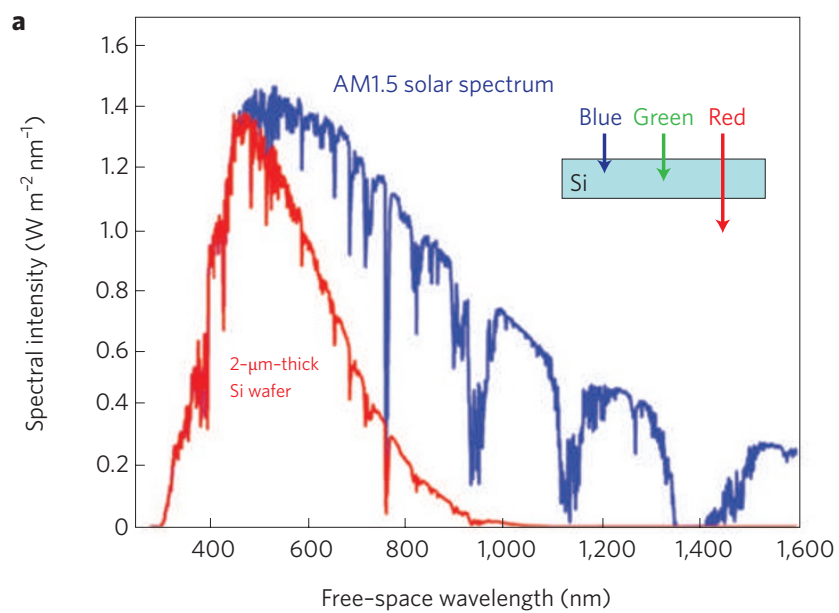

